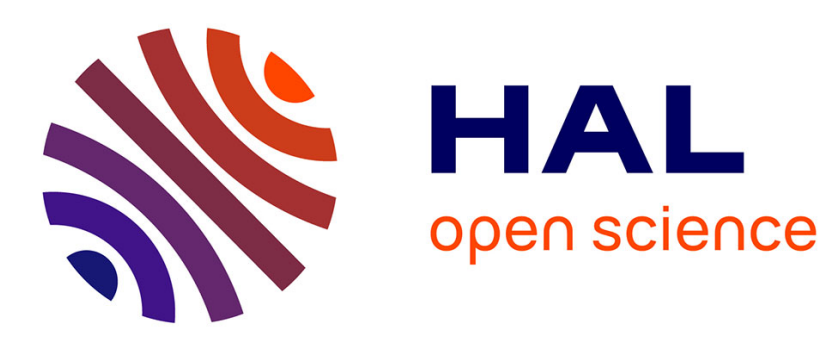

\title{
A Model of Martensitic Unelasticity Accounting for the Crystal Symmetry of the Material
}

\author{
I. Erglis, V. Ermolayev, A. Volkov
}

\section{To cite this version:}

I. Erglis, V. Ermolayev, A. Volkov. A Model of Martensitic Unelasticity Accounting for the Crystal Symmetry of the Material. Journal de Physique IV Proceedings, 1995, 05 (C8), pp.C8-239-C8-244. 10.1051/jp4:1995833 . jpa-00254082

\section{HAL Id: jpa-00254082 https://hal.science/jpa-00254082}

Submitted on 1 Jan 1995

HAL is a multi-disciplinary open access archive for the deposit and dissemination of scientific research documents, whether they are published or not. The documents may come from teaching and research institutions in France or abroad, or from public or private research centers.
L'archive ouverte pluridisciplinaire HAL, est destinée au dépôt et à la diffusion de documents scientifiques de niveau recherche, publiés ou non, émanant des établissements d'enseignement et de recherche français ou étrangers, des laboratoires publics ou privés. 


\title{
A Model of Martensitic Unelasticity Accounting for the Crystal Symmetry of the Material
}

\author{
I.V. Erglis, V.A. Ermolayev and A.E. Volkov \\ Res. Inst. Math. Mech. (NIIMM) St.-Petersburg State Univ., Bibliotechnaya pl. 2, Petrodvorets, \\ 198904 St.-Petersburg, Russia
}

\begin{abstract}
An approach is presented to describe the mechanical behavior of the shape memory materials. On the one hand it uses the basic concepts of the structure-analytical theory proposed by V.A.Likhachev and V.G.Malinin which are the formulation of the constitutive equations of the phase transformation and martensitic unelasticity for micro regions and the orientation averaging of micro strains to obtain the macro strain. On the other hand the averaging procedure is arranged in a way to account for the crystal symmetry of the material. Results are presented of the computer simulation of pseudoelasticity, shape memory effect and active straining of a shape memory material with a thermoelastic martensitic transformation. These are stress-strain diagrams at various temperatures, temperature dependencies of the martensitic unelastic strain. All the results show good qualitative agreement with the experiments in which dislocation plasticity does not play a significant role.
\end{abstract}

\section{INTRODUCTION.}

In recent time many approaches have appeared which can descibe the mechanical behaviour of alloys with martensitic transformations. These works account for various features of martensitic transformation. In [1-3] the description of materials with martensitic transformations is built based mainly on the thermodynamical aspects of transformations. An entirely mechanical approach has been developed in [4]. Large success has been achieved in describing the strain of an alloy due to pseudoelasticity, transformation plasticity and strain recovery. One of the most successful was the structure-analytical theory of plasticity and strength [5,6] which tries to combine physical and mecanical approaches to this problem. The deformation is considered as a process developing on two levels: macroscopic - in which ensembles of grains are considered as points of the medium - and microscopic in which separate martensite single crystals are distinguished. The observed macroscopic strain is then the mean value of micro strains. Kinetics of the microstrain is described by some differential equations accounting for the basic phenomenological data on the transformation kinetics. The difficulties of the space averaging procedure are overcome by its replacing to the orientation averaging as in the theory of slip. This approach has managed to model qualitatively the deformation of an alloy with martensitic transformations of the first order under simultaneous action of varying stress and temperature. The present work makes an attempt to bring the structure- 
analytical theory closer to crystallographical aspects of the transformation and thus to obtain better agreement with experimental data. It differs by the averaging procedure which is organized in a way to account for the possibility of realizing in the same grain of several crystallografically equivalent variants of the transformation. This has allowed to obtain better quantitative agreement with experimental data on titanium nickel mechanical bchaviour.

\section{FORMULATION OF THE MODEL}

We base on the following very simple assumptions about the martensically unelastic material. We consider that it consists of grains numbered $1,2, \ldots, \omega, \ldots, \Omega$ each being a single crystal. In a grain martensite can appear in $\mathrm{N}$ crystallografically equivalent variants characterised by transformation strains

$$
\mathrm{D}_{\mathrm{n}}=\mathrm{P}_{\mathrm{n}} \mathrm{DP} \mathrm{P}_{\mathrm{n}}^{-1}, \quad \mathrm{n}=1,2, \ldots, \mathrm{N}
$$

where $D$ is the transformation strain matrix for one of the variants referred to the crystal physical basis of austenite; $P_{n}, n=1,2, \ldots, N$ are rotation matrixes belonging to austenite crystal symmetry group and $D_{n}$ is the strain matrix for the $n$-th variant. We imply that transformation strain is the pure (Bain's) strain of the transformation. The amount of martensite obtained through the $n$-th variant we will characterize by the quantity $\Phi_{\mathbf{n}}$ such that $(1 / N) \Phi_{n}$ is the volume fracture of this martensite. If the transformation occurred in an unstressed grain then all martensite variants would occupy equal volumes and their volume fracture would be $1 / N$. Thus $\Phi_{n}$ is the ratio of the volume of the $n$-th martensite variant to the volume it would occupy if the transformation had occurred in an unstressed grain.

The mean strain matrix $\varepsilon^{\text {gr }}$ of a grain due to the transformation in these notations is

$$
\varepsilon^{\mathrm{gr}}=\frac{1}{N} \sum_{n=1}^{N} \Phi_{n} D_{n}
$$

Passing to the laboratory basis and averaging the strain of all the grains we will calculate the macroscopic martensitically unelastic (martensitic) strain matrix $\varepsilon^{m}$. of the material:

$$
\varepsilon^{\mathrm{m}}=\frac{1}{\Omega} \sum_{\omega=1}^{\Omega} \mathrm{R}_{\omega} \varepsilon_{\omega}^{\mathrm{gr}} \mathrm{R}_{\omega}^{-1}
$$

where $\varepsilon_{\omega}^{g r}$ is the mean strain matrix in the grain number $\omega$ and $R_{\omega}$ is the rotation matrix turning the laboratory basis into the crystal physical basis of grain $\omega$. 
The evolution law for $\Phi_{n}$ in any of the grains was the same as in the structureanalytical theory $[5,6]$ :

$$
\begin{aligned}
\Phi_{n} & =-\frac{\dot{T}^{*}}{M_{s}-M_{f}} H\left(-\dot{T}^{*}\right) H\left(1-\Phi^{g r}\right) H\left(M_{s}-\left(M_{s}-M_{f}\right) \Phi_{n}-T^{*}\right)- \\
& -\frac{T^{*}}{A_{f}-A_{s}} H\left(\dot{T}^{*}\right) H\left(\Phi_{n}\right) H\left(T^{*}+\left(A_{f}-A_{s}\right) \Phi_{n}-A_{f}\right)
\end{aligned}
$$

where $M_{s}, M_{f}, A_{s}, A_{f}$ are the characteristic temperatures of the martensitic transformation, $\mathrm{H}$ is the Heaviside's function, $\Phi^{\mathrm{gr}}=\frac{1}{N} \sum_{\mathrm{u}=1}^{N} \Phi_{\mathrm{n}}$ is the volume fraction of martensite in this grain and $T_{n}^{*}$ is the effecftive temperature for the $n$-th martensite variant. It is inroduced into theory to account for the stress effect on the transformation. In conformity with the Clausius - Clapeiron equation it is determined by the formula

$$
T_{n}^{*}=T+\frac{\tau \cdots D_{n}}{q_{0}}
$$

where $T$ is the absolute temperature, $T_{0}$ is the phase equilibrium temperature, $q_{0}$ is the enthalpy of the transformation (negative for the direct transformation in TiNi) and $\tau$ is the stress matrix in the crystal physical basis of the grain.

The elastic strain of the material was calculated by isotropic Hook's law independently for martensite $\left(\varepsilon^{\mathrm{el}, \mathrm{M}}\right.$ ) and austenite $\left(\varepsilon^{\mathrm{el} . \mathrm{A}}\right)$ and the mean elastic strain $\varepsilon^{\mathrm{el}}$ was calculated with the use of the mixture rule:

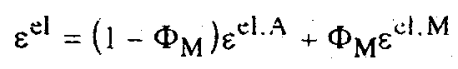

where $\Phi_{M}=(1 / \Omega) \sum \Phi_{(1)}^{g r}$ is the volume fraction of martensite. the sum taken on all the grains.

\section{RESULTS OF MODELLING.}

The described above model has heen applied to simulate the main phenomena of martensitic unelasticity. namely active axial loading at various temperatures, transformation plasticity when colling the stressed material, strain recovery in the course of the reverse transtormation. The model material consisted of 100 grains orientations of which were uniformly distributed in the orientation space. The austenite grain lattice was assumed to he cubic with 24 elements of symmery. The deviator pirt of the transformation strain $D$ 
descrihing the B2 - B19' transformation in TiNi was taken from 17$]$ and its isotropic pant was chosen to give the transformation dilatation equal $-0.34 \%$ as it is in TiNi. Other transformation characteristics ivere: $M_{S}=300 \mathrm{~K} . M_{f}=280 \mathrm{~K}, A_{S}=340 \mathrm{~K} . A_{f}=360 \mathrm{~K}$. $\mathrm{T}_{0}=330 \mathrm{~K} \cdot \mathrm{q}_{0}=-200 \mathrm{MJ} / \mathrm{m}^{3}$. Young's noduli were $68 \mathrm{GPa}$ for martensite and $74 \mathrm{GPa}$ for austenite. Poisson's ratios equaled 0.48 and 0.33 respectively. No adjusting constants were used. Heat expansion and dislocation plasticity were not taken into account so the results where stress exceeds dislocation flow limit of course can not be compared with the real experiment.

Stress - strain diagrams (fig. 1) show good qualitative agreement with the experiment and the same order of strain values. At $T>A_{f}$ there is full psudoelastic strain recovery and the residual strain is present after unloading at $T<A_{f}$.

The transformation plasticity in cooling and the strain recovery in consequent heating is shown in fig. 2 and fig. 3 . When the material is "cooled" without stress it accumulates a small negative strain due to the dilatation effect of the transformation. We have tested that if the transformation strain tensor is replaced by its deviator no strain is produced in cooling. When the transformation plasticity strain was produced at small stresses one can see kinetics of the stain recovery normally observed in experiments, that is the recovery temperatures are higher than those of the strain accumulation in preceding cooling under a constant stress. (fig.3a). But when the same model experiment was held for greater stresses (curve for $600 \mathrm{MPa}$ in fig. $3 \mathrm{~b}$ ), character of the accumulation - recovery kinetics changed and the recovery branch of the graph lay to the left of the accumulation one. This happened when the stress was nearer to the values delivering saturation to the maximum transformation plasticity strain as function of the stress. This dependence is plotted in fig 4 and it is linear for small values of the stress (not exceeding $250 \mathrm{MPa}$ ). In fig3 one can also notice a considerable shift with the stress of the strain production start and strain recovery finish temperatures and a very weak stress dependence of the strain production finish and strain recovery start temperatures.

Fig.5 shows quite ordinary strain recovery after residual strain had been produced in the material by tension at $280 \mathrm{~K}$ (that is at $\mathrm{M}_{\mathrm{f}}$ ). Shift of the strain recovery start temperature with the growth of residual strain can be observed. Fig.6 illustrates huating under a constant stress. On the first stage the strain is accumulated in the direction of the stress and on the second stuge it recovers. The explatiation of this phenomenon is that martensite obtained by cooling of the unstressed material consists of crystallites helonging (1) all the variants of the trimstomation. When it is heated under a stress first tum into uustenite the crystallites the reverse transformation strain of which delivers maximum work w the applied strss. On the linal stages of the transformation all the martensite crystallites disappear with the full strain recovery.

\section{CONCLUSION and ACKNOIVLEDGEMENTS}

The results of computer modelling presented above show that the proposed approach possesses all positive features of the structure-analytical theory. It correctly describes all main aspects of shape menniey metierials mechanical behavior such as the wetise 


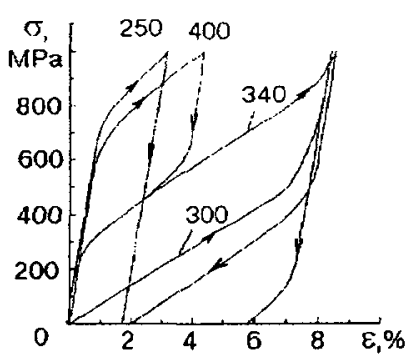

Figure 1. Calculated stress-strain diagrams at various temperatures (figures at curves in $\mathrm{K}$ ).

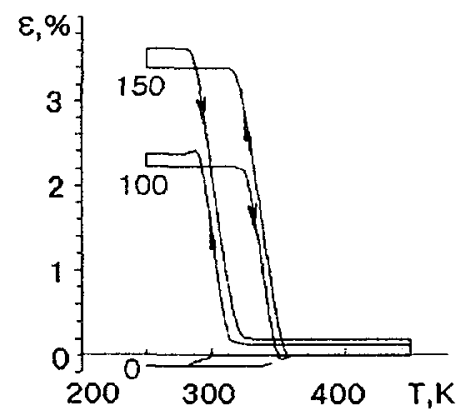

a)

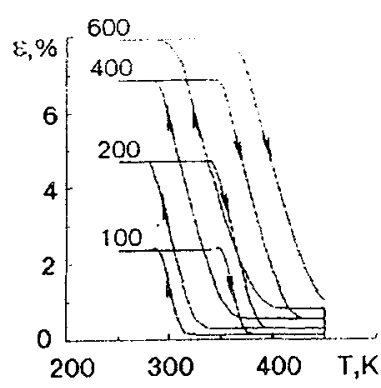

Figure 2. Strain versus temperature in cooling and heating under various constant stresses (figures at curves in MPa)

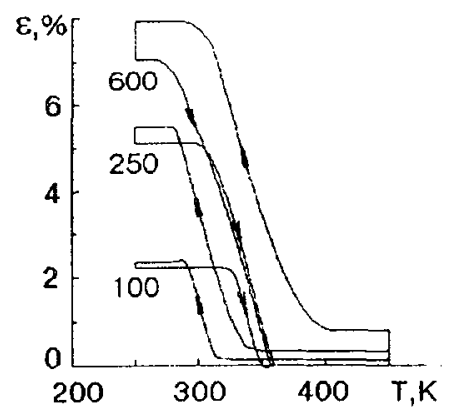

b)

Figure 3. Strain versus temperature for transformation plasticity in cooling under various constant stresses (figures at curves in $\mathrm{MPa}$ ) and strain recovery in heating of the unstressed material. $a$ - small stresses, $b$ laiger stresses.

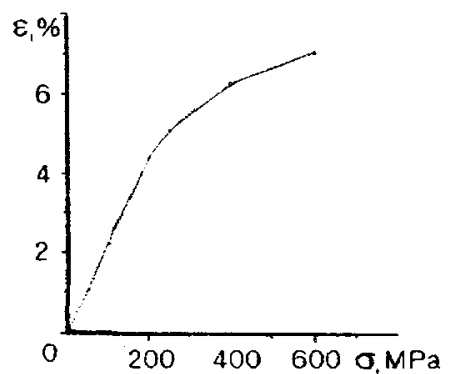

Figure 4. Dependence of the maximum uansformation plasticity stain on the stress in cooling.

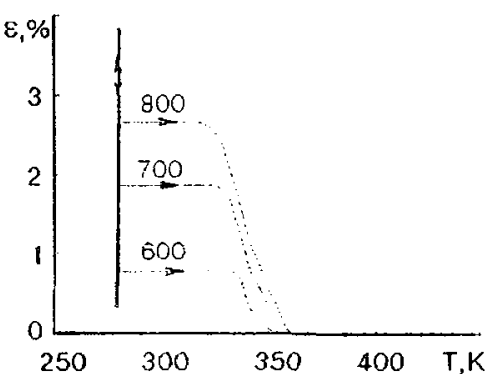

Figure 5. Suain recovery alict active axial loading by various stresses (figures al curves in MPa) of martensitc at $280 \mathrm{~K}$. 


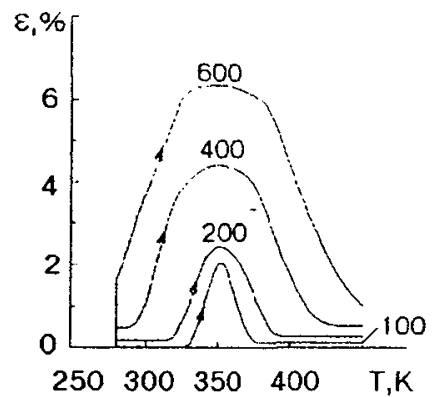

Figure 6. Strain dependence on temperature for model material loaded by various stresses (figures at curves in $\mathrm{MPa}$ ) at $250 \mathrm{~K}$ and heated. deformation at various temperatures. transformation plasticity and shape memory effect. At the same time it demonstrates better quantitative agreement with experiments concerning the transformation plasticity strain and the shift of temperatures at which strain variation start and finish is observed.

The authors are grateful to V.A.Likhachev for useful discussions.

\section{References}

1. Patoor E., Bensalah M.O., Berveiller M. Mem. et etudes Sci. Rev. Met. 89 (1992) 527.

2. Lexcellent C., Torra V., Raniecki B. Journal de Physique Sec. 3. 3 (1993) 1463 - 1477

3. Ortin J., Planes A. Acta Metall. 37 (1989) 1433-1441.

4. Bertram A. Nucl. Eng. Design. 74 (1982). 173-182.

5. Likhachev V.A., Malinin V.G. Structure- analytical theory of strength. (in Russian) (Nauka, St.-Petersburg, 1993) 471 p.

6. Likhachev V.A., Malinin V.G. Izvestia Vuzov. Fizika, (1990), N 2, $121-138$.

7. Knowles K.M. Smith D.A. Acta metall. 29 (1981). 101-110. 